\title{
Marketing Research on the Correct Use of Nebulizers Based on the Results of a Questionnaire Survey of Customers
}

\author{
${ }^{1}$ Pharmaceutical Faculty, Ryazan State Medical University, Ryazan, Russia \\ ${ }^{2}$ Faculty of Ecology and Engineering, Sochi State University, Sochi, Russia \\ *Corresponding author.Email: vlvas@mail.ru
}

Kharchenko G.A. ${ }^{1}$ Klischenko M.Yu. ${ }^{1}$ Grigorieva I.V. ${ }^{1}$ Kovalenko V.V. ${ }^{* *}$

\begin{abstract}
The authors set a goal to study the correct use of devices for inhalation by consumers on the basis of statistical processing of the results of a questionnaire survey of customers on the basis of contingency tables. The analysis showed that most consumers, when buying inhalers, consult with a doctor about the choice of the inhaler type and the drugs used; however, with ARVI and influenza diseases, half of the respondents selfmedicate. It was revealed that the majority of respondents use medications prescribed by a doctor. Still, it is alarming that antibiotics and hormones are used in self-medication, although the cases are rare. It was also found that most respondents comply with the instructions for the use of inhalers, clean the device after use, but only a third of the respondents disinfect the parts of the device after the manipulation. The vast majority of respondents noted the effectiveness, safety, ease of use of nebulizers, minimizing side effects. Approximately one fifth of the respondents attributed to inhalers such deficiencies as the cost and complexity of their use (the need for an electric power source, strict requirements for proper care).
\end{abstract}

Keywords: nebulizer, questionnaire, marketing research, coronavirus, COVID-19.

\section{INTRODUCTION}

One of the directions in the development of medicine is targeted methods of drug delivery. This becomes especially important in urgent situations when it is necessary to minimize the time from the moment of drug administration to the onset of the effect, as well as in cases where there is a need to use relatively large doses of the drug and reduce its systemic effects in order to avoid the development of undesirable effects, for example, in the treatment of COVID-19 disease and subsequent rehabilitation.

The effectiveness of therapy depends on the properties of the resulting aerosol, and, consequently, on the device that produces and delivers it to the respiratory tract. An ideal apparatus should ensure the rapid production of aerosol, its delivery to the respiratory tract and alveoli with minimal loss of the drug, be simple enough to use, reliable and affordable for use at any age and at various stages of various diseases. Nebulizers are effective and convenient for the treatment of respiratory symptoms in patients with diseases of both the upper and lower respiratory tract, suitable at any age, since they do not require special skills in the technique of inhalation [1].
It is known that the absorption of drugs through the mucous membrane of the respiratory tract occurs 20 times faster than when taking the tablet form. Many drugs can be delivered to the lungs as an aerosol. The therapeutic effect of drugs in the form of an aerosol due to the large total area of exposure is achieved with a lower dose of the substance, despite the fact that the maximum concentration of the drug substance is concentrated in the pathology zone [2], thereby the nebulizer increases the effectiveness of the drugs used.

The inhalation method using compressor-type nebulizers is the main method for delivering bronchodilator and anti-inflammatory drugs for bronchial obstructive syndrome (BOS) against acute respiratory viral infections, influenza [3]. The nebulizer is the optimal system for delivering drugs to the respiratory tract in patients with biofeedback in young children. Its use contributes to the best dynamics of clinical data, a sufficient bronchodilating effect of the peripheral parts of the bronchi, and the technique of its use is practically error-free $[4,5]$. The most technologically advanced is a new generation nebulizer (mesh nebulizer), which uses a fundamentally new device-a vibrating membranewhich significantly increases the efficiency and convenience of inhalation [6].

The European Respiratory Society pays great attention to the use of nebulizers in the treatment of diseases of the 
chest organs, including the availability of complete instructions for use, maintenance and cleaning [7].

The use of aerosol therapy for the treatment of various pulmonary diseases is a common practice in European countries, nebulizers are used to administer bronchodilators, steroids and antibiotics [8].

The recommendations of the Moscow Department of Health indicate that the use of a nebulizer for coronavirus COVID-19 is indicated for the inhalation treatment of biofeedback using solutions with salbutamol, phenoterol, combined drugs (ipratropium bromide + phenoterol) [9].

Currently, nebulizer therapy has justifiably become an important component in the treatment of most acute and chronic respiratory diseases.

However, some procedures that are potentially capable of generating aerosols are a risk factor for the transmission of viral infection to health workers involved in the treatment of infected patients [10,11], since the virus is easily transferred from one object to another in an environment of small particles of sprayed liquid.

Classification of devices for inhalation, as well as marketing research on their consumer properties, the authors have performed earlier [12, 13].

The purpose of the study is to find out the correct use of inhalers. Based on the statistical processing of the results of a questionnaire survey of buyers, it was necessary to identify:

- the degree of responsibility of respondents when using inhalers, in particular for self-medication.

- diseases and symptoms in which inhalers are most often used in everyday life.

- compliance with the rules for inhaler use (compliance with manuals: the rules of operation, cleaning and disinfection of the device).

- the opinion of respondents about the shortcomings and advantages of inhalers.

\section{MATHERIALS AND METHODS}

Statistical processing of the survey results is based on contingency tables, since the type of data obtained is nominal. A survey of 106 respondents who planned the acquisition of inhalers was conducted. The respondents were visitors to pharmacy organizations located in the central regions of the Russian Federation.

Questioning of inhaler buyers reveals compliance with the instructions and prescriptions of a doctor for treatment, the frequency of use of a nebulizer for self-medication, the opinion of customers about the advantages and disadvantages of devices, which will further improve the effectiveness of pharmaceutical counseling when selling nebulizers.

The analysis of hypotheses showed that for a number of signs the statistical relationship is not reliable $(p>0.05)$, therefore, these hypotheses are excluded from the discussion:

- Do the answers to questions regarding compliance with the instructions for the use of inhaler and the type of apparatus used for inhalation differ significantly?

- Do the answers to questions about the benefits of inhalation therapy and the use of inhalers in the treatment of certain diseases differ significantly?

- Do the answers to questions about compliance with the requirements of the instructions and the use of inhalers with certain symptoms of diseases differ significantly?

- Do the answers to questions about the relationship between the type of nebulizer used and the advantages of inhalation therapy over other treatment methods differ significantly.

\section{RESULTS AND DISCUSSION}

\subsection{General Information about Respondents}

Figure 1 presents a comprehensive assessment of the sex and age characteristics of respondents. Of the total number of respondents, $83.17 \%$ are women, who are distributed by age as follows: $31.5 \%$ are women under the age of 30 , which can be explained by the care of young mothers, first of all, about children's health; $12.36 \%$ are from 31 to 40 ; $17.97 \%$ are from 41 to $50 ; 20.2 \%$ are from 51 to 60 ; $17.97 \%$ are over 60 years old.

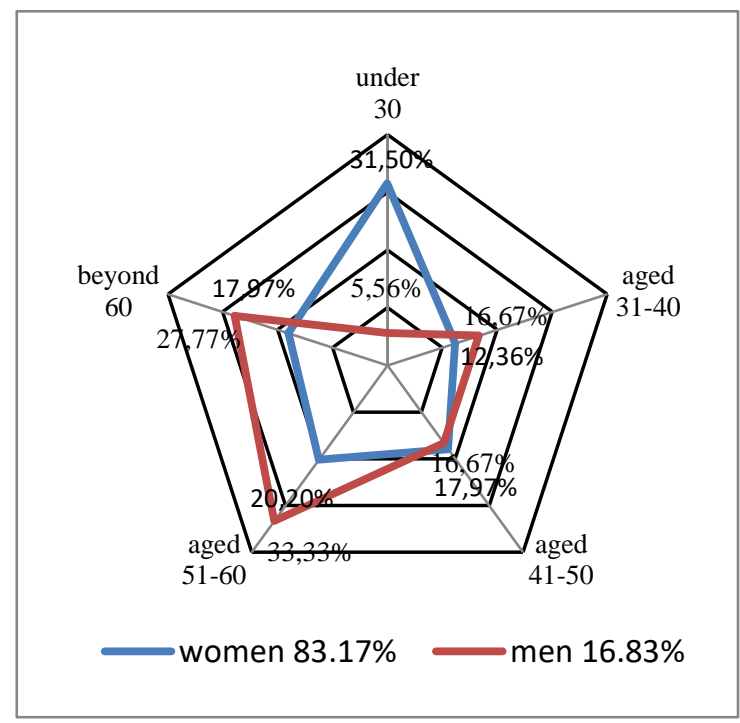

Figure 1 Distribution of respondents by gender and age

Men who participated in the survey are much fewer (only $16.83 \%$ ), which is associated with the general trend: men are less likely to visit pharmacy organizations. According to age groups, they were distributed as follows: $5.56 \%$ were male respondents under the age of $30 ; 16.67 \%$ were from 31 to $40 ; 16.67 \%$ were from 41 to $50 ; 33.32 \%$ 
were from 51 to $60 ; 27.78 \%$ were over 60 years old. Men, basically, only after 50 years old begin to be interested in inhalation technology in connection with emerging chronic diseases.

About $80 \%$ (87/106) of respondents at the time of the survey had experience working with inhalers and were able to answer questions regarding not only the choice, but also questions about the medical use of certain groups of drugs, the use and sanitization of devices. Some respondents did not answer all the questions posed, so the number of respondents may vary in individual questions. For example, some respondents did not know the classification and names of drugs.

\subsection{The degree of responsibility of respondents when using inhalers}

Overall, $79 \%$ of respondents are responsible for the use of inhalers, seek medical advice or use the inhaler as directed by a doctor. Respondents with inflammatory diseases of the upper and lower respiratory tracts mostly consult a doctor ( $86 \%$ and $70 \%$, respectively). The use of the inhaler "at your own peril and risk" by individual respondents without consulting a doctor may be due to a lack of time to visit a doctor and/or an abundance of information on treatment on the Internet.

In the treatment of acute respiratory viral infections and influenza, respondents show more independence, and not always $(53 \%)$ consider it necessary to seek advice from a doctor on the use of the inhaler. This reflects the general tendency of ARVI and influenza self-treatment by the population of our country. Many people suffer diseases on the go, use their own experience in treating such diseases, the advice of friends, etc., underestimating the severity of viral infections in general and a large number of complications.

A special group consists of respondents with occupational respiratory diseases. The treatment of occupational diseases of the respiratory tract, pharyngomycosis requires a mandatory visit to a doctor (for the diagnosis of the disease, a thorough examination by a qualified specialist, selection of a treatment regimen). All respondents suffering from occupational diseases indicated that they use inhalers on the recommendation of a doctor.

\subsection{Use of inhalers for various respiratory}

\section{diseases}

The number of respondents using inhalers in the treatment of upper respiratory tract (URT) amounted to slightly more than half of the total number of respondents $(51 \%)$, in the remaining three groups (ARVI/influenza, lower respiratory tract diseases, occupational diseases) the number of respondents differs slightly: $20 \%, 12 \%$ and $17 \%$, respectively.
Respondents under the age of 50 years use inhalers mainly in the treatment of acute respiratory viral infections/influenza and in diseases of the UDT (73-80\%, depending on the age group). Respondents older than 50 years more often use inhalers for occupational diseases (Table 1).

Table 1 Conjugation table for signs: respondents age and disease group $(\mathrm{p}=0.016)(\%$ for each age group $)$

\begin{tabular}{|l|l|l|l|l|}
\hline \multirow{2}{*}{ Age } & \multicolumn{4}{|l|}{ Group of diseases } \\
\cline { 2 - 5 } & $\begin{array}{l}\text { ARVI, } \\
\text { influenz } \\
\text { a }\end{array}$ & URTI & LRTI & $\begin{array}{l}\text { Occupat } \\
\text { ional } \\
\text { diseases }\end{array}$ \\
\hline $\begin{array}{l}\text { under } \\
30\end{array}$ & 42 & 32 & 21 & 5 \\
\hline $31-40$ & 33 & 40 & 20 & 7 \\
\hline $41-50$ & 23 & 59 & 6 & 12 \\
\hline $51-60$ & 0 & 65 & 5 & 30 \\
\hline $\begin{array}{l}\text { beyond } \\
60\end{array}$ & 6 & 56 & 6 & 32 \\
\hline Total & 21 & 51 & 11 & 17 \\
\hline
\end{tabular}

Almost half of men (44\%) use inhalers for occupational diseases and exclusively as directed by a doctor. Women use them more widely: $49 \%$ for airborne diseases, $25 \%$ for acute respiratory viral infections and influenza, $14 \%$ for diseases of the LRT, $11 \%$ for occupational diseases.

In general, respondents use inhalers to relieve cough symptoms (separately and in combination with other symptoms) in $82 \%$ of cases, $52 \%$ use them for runny nose (separately and in combination with other symptoms), $32 \%$ only for cough relieve, $18 \%$ only for sore throat.

In the treatment of acute respiratory viral infections and influenza, LRTIs, $50 \%$ of respondents use inhalers to relieve symptoms of cough and runny nose; $59 \%$ of them, for diseases of the airborne diseases to relieve only cough; $23 \%$, to relieve cough and runny nose. In the group of occupational diseases, $93 \%$ of respondents use inhalers to relieve sore throat.

For inhalation, $78 \%$ of the total number of respondents use medications prescribed by a doctor. After consultation with a doctor, $95 \%$ of respondents use prescribed medications. When treating diseases such as acute respiratory viral infections, influenza (the most common), $56 \%$ follow the doctor's prescription when choosing a medication for inhalation, 33\% choose it by themselves, only $11 \%$ of respondents trust the Internet (Table 2).

For diseases of the UDT (tracheitis, adenoiditis, sinusitis, tonsillitis, etc.) people are more serious; they understand the possibility of complications, $82 \%$ use drugs recommended by a doctor. 
Among the respondents who use inhalers to treat diseases of the lower respiratory tract (pneumonia, bronchial asthma, etc.), $70 \%$ of respondents tend to follow the doctor's recommendations and use drugs prescribed by the doctor. All respondents with occupational diseases use drugs prescribed by a doctor during treatment.

Table 2 Conjugation table for signs: method of drug selection and group of diseases $(p=0.023)$ (\% for each age group)

\begin{tabular}{|l|l|l|l|l|}
\hline \multirow{2}{*}{ Disease group } & \multicolumn{4}{|c|}{ Method of medication selection } \\
\cline { 2 - 5 } & $\begin{array}{l}\text { Advised } \\
\text { by doctor }\end{array}$ & $\begin{array}{l}\text { Own } \\
\text { choice }\end{array}$ & $\begin{array}{l}\text { Found on } \\
\text { internet }\end{array}$ & Total \\
\hline $\begin{array}{l}\text { ARVI, } \\
\text { influenza }\end{array}$ & 56 & 33 & 11 & 21 \\
\hline URTI & 82 & 9 & 9 & 51 \\
\hline LRTI & 70 & 10 & 20 & 11 \\
\hline $\begin{array}{l}\text { Occupational } \\
\text { diseases }\end{array}$ & 15 & 0 & 0 & 17 \\
\hline Total & 78 & 13 & 9 & 100 \\
\hline
\end{tabular}

For statistical data processing, the list of drugs used for inhalation was divided into five groups. The group of drugs containing hormonal drugs and combinations containing hormonal drugs is used more often $(28 \%)$, the remaining four groups of drugs (antibiotics, antiseptics, mucolytics, mineral waters/sodium chloride isotonic solution) are used almost equally frequently (15-20\%).

It should be noted that referrals to a doctor are usually associated with the presence of serious diseases, and respondents who have turned to a doctor use hormonal drugs $(34 \%)$ and antibiotics $(23 \%)$ to a greater extent. Among the respondents who did not seek medical advice, the most popular are mineral water and mucolytics (33\%), antiseptics $(33 \%)$, and their complex combination. It is alarming that antibiotics $(1.2 \%)$ and hormones $(2.4 \%)$ are used as part of self-medication. Respondents who use Internet resources as a consultant rather than a doctor most often used antiseptic drugs or their combination with mucolytics.

\subsection{Compliance with ADI}

In general, the majority of respondents (89\%) comply with the instructions for the use of inhalers, of which $83 \%$ of respondents previously consulted with a doctor. This suggests that the majority of respondents responsibly approach the use of inhalers. Only 7\% of respondents did not consult a doctor and did not responsibly approach the use of inhalers, not considering it necessary to clearly comply with the requirements of the instructions.
$78 \%$ of respondents consult a doctor and use inhaler as prescribed by a doctor, of which $94 \%$ indicate that they follow the instructions for use. Of those respondents who did not consult a doctor, $70 \%$ still follow the instructions, which is important.

Of the respondents using drugs prescribed by a doctor, 93\% comply with the instructions for the use of inhalers. $22 \%$ of respondents independently choose drugs, including using the Internet and the advice of acquaintances, and a fourth $(26 \%)$ of them do not consider it necessary to study the instructions for using the device.

$11 \%$ of respondents do not comply with the instructions for using the inhaler. Life experience shows that people do not like instructions because of the complexity of the presentation of the material in them, the length of the text, the use of language with an abundance of professional terminology. Employees of pharmacies note that buyers who come with a complaint about a malfunction of the inhaler sometimes simply have not studied the instructions, have not learned how to use it and ask questions that are described in detail in the instructions.

In general, the majority of consumers who participated in the survey $(82 \%)$ are responsible for treatment: they follow the instructions, use drugs prescribed by the doctor. They choose the drug for treatment themselves, but at the same time, only $11.7 \%$ of the respondents follow all the instructions.

An important part of the instructions for use of the nebulizer is its sanitization. Respondents who had previously used a nebulizer at home indicated that they clean it after use (98\%). At the same time, half of them $(48 \%)$ soak and wash parts in warm water, $26 \%$ wash parts in running water, $21 \%$ pour it with boiling water.

After manipulation, only $44 \%$ of respondents who clean the device carry out disinfection of parts of the device. Of these, the bulk of the respondents $(76 \%)$ boil the parts, $17 \%$ treat it with $3 \%$ hydrogen peroxide solution for 30 minutes, the remaining $7 \%$ treat it with $3 \%$ chloramine solution.

The analysis of the contents of the ADI instructions of different brands and manufacturers showed that, as a rule, it is recommended to clean and disinfect individual parts of it before use and during use. The technique of cleaning a nebulizer involves a set of actions: wash your hands with soap; disassemble the inhaler into parts (usually a mask/mouthpiece, tube, atomizer), rinse thoroughly (within a minute) the components with warm water using a mild detergent and then rinse them under a stream of clean hot water after each use (otherwise the drug residue dries, which can lead to ineffective operation of the device); put the washed parts on a dry, clean, lint-free towel (paper one), put the dried parts in the packaging. If the compressor itself becomes dirty, wipe it with a soft cloth/gauze soaked in water or a mild detergent. 
Disinfection of individual parts (mouthpiece, nose nozzle, face mask, drug reservoir, and other parts of the nebulizer chamber) is recommended before first use or after prolonged storage. If the device is used by several people, it is disinfected after each use or daily after the last treatment session when used by one person.

For disinfection, a chemical method can be used. Disinfectants are (in accordance with the manufacturer's instructions): solutions of chlorhexidine, sodium hypochlorite, alcohol, amphoteric surfactants, etc. In the instructions of some manufacturers there, is a recommendation to wipe the accessories of the device with a $3 \%$ solution of hydrogen peroxide with the addition of a $0.5 \%$ solution of detergent (for example, washing powder, liquid soap).

Methods of both wiping and immersing parts in a solution are proposed. Disinfection of individual parts can be carried out by boiling (thermal method) for 10 to 30 minutes (it is necessary to monitor the amount of water, lack of water can lead to deformation of the parts), carefully remove the parts after boiling, shake off excess moisture from them and allow to dry. This procedure should be preferred if the manufacturer allows the device to be processed in this way and does not prohibit exposure to high temperatures.

It should be noted that when choosing a disinfection method, it is necessary to be guided exclusively by the instructions for use of the purchased device.

\subsection{Respondents' opinion on the disadvantages and advantages of inhalation apparatuses}

When questioned, respondents had the opportunity to note several shortcomings or advantages. $39 \%$ of respondents believe that nebulizers have some flaws. Of these, $46 \%$ consider the device expensive (only $18 \%$ of the total number of respondents), $41 \%$ find them difficult to use (requires a source of electricity, proper care requirements). Assessing the advantages of inhalation therapy in comparison with other treatment methods, respondents $(82 \%)$ noted its effectiveness and safety, ease of use and minimization of side effects, and in most of the questionnaires the whole range of advantages was reflected.

\section{CONCLUSION}

Based on a questionnaire survey of inhaler buyers, the following patterns were identified, the reliability of which is confirmed by the results of statistical processing:

- most often respondents use inhalers for diseases of the upper respiratory tract;

- the majority of respondents when buying an inhaler consult with a doctor on the choice of its type and the drugs used; however, with ARVI and influenza diseases, half of the respondents self-medicate;

- in general, the majority of respondents use inhaler for the treatment of cough, both an independent symptom and complex symptoms;

- the majority of respondents use drugs prescribed by a doctor; however, it is alarming that with self-medication, although rarely, antibiotics and hormones are used;

- the majority of respondents comply with the instructions for the use of inhalers, clean them device after use, but only a third of the respondents disinfect the parts of the device after the manipulation, forgetting that neglecting the rules of care puts them and their loved ones at risk of reinfection;

- the majority of respondents noted the effectiveness and safety of inhalers, as well as ease of use and minimization of side effects, and the full range of advantages was reflected in the questionnaires of more than half of the respondents.

- less than one fifth of the respondents drew attention to the shortcomings of inhalers and highlighted the cost and complexity of the application (a source of electricity, the requirements for proper care).

Thus, as a result of the study, the goal was achieved and the tasks set were solved. Knowing the mistakes made by buyers, pharmacy specialists can correctly build a pharmaceutical consultation algorithm, drawing attention to the need to consult with a doctor on the selection of an inhaler and drugs, the importance of observing the requirements of the instructions for inhalation techniques, cleaning and disinfection of individual parts of the device.

\section{REFERENCES}

[1] D. Posa, A. Pizzulli, P. Wagner, S. Perna, S. Hofmaier, P.M. Matricardi, S. Lau, Efficacy and usability of a novel nebulizer targeting both upper and lower airways, in: Italian Journal of Pediatrics, 2017, vol. 43, p. 89/ https://ijponline.biomedcentral.com/articles/10.118 6/s13052-017-0400-x

[2] M.A. Kutsenko, A.G. Chuchalin, Nebulaizery i ingaliatsionnaia terapiia $\mathrm{v}$ pul'monologicheskoi praktike [Nebulizers and inhalation therapy in pulmonary practice], RMZh 29 (2013) 1440-5. https://www.rmj.ru/articles/bolezni_dykhatelnykh_ putey/Nebulayzery_i_ingalyacionnaya_terapiya_v_ pulymonologicheskoy_praktike/.

[3] L.V. Kramar, T.Yu. Larina, Treatment of acute respiratory viral infections complicated by bronchial obstructive syndrome in children, Volgograd Medical Journal 2 (2016) 43-46, https://cyberleninka.ru/article/n/lechenie-ostryhrespiratornyh-virusnyh-infektsiy-oslozhnennyhbronhoobstruktivnym-sindromom-u-detey.

[4] C.V. Zaitseva, O.A. Murtazaeva, Syndrome of bronchial obstruction in children, in: Difficult patient, vol. 10, (2-3) (2012) 34-38. http://tpacient.ru/articles/459/.

[5] M.V. Lim, The combined use of acetylcysteine and $3 \%$ of sodium chloride in the nebulizer therapy of acute bronchiolitis, in: European science review. 
(11-12) (2016)

$63-66$. http://dx.doi.org/10.20534/ESR-16-11.12-63-66.

[6] O.V. Fesenko, Opportunities of modern mesh nebulizers use, Consilium Medicum 20 (11) (2018) $52-54$. https://cyberleninka.ru/article/n/vozmozhnostisovremennyh-mesh-nebulayzerov.

[7] J. Boe, J. H. Dennis, B.R. O'Driscoll, T.T. Bauer, M. Carone, B. Dautzenberg et al. European Respiratory Society Guidelines on the use of nebulizers, European Respiratory Journal 18 (2001) 228-242. https://doi.org/10,1183/09031936.01.00220001.

[8] S. Ehrmann, F. Roche-Campo, G.F Sferrazza Papa, D. Isabey, L. Brochard, G. Apiou-Sbirlea, et al. Aerosol therapy during mechanical ventilation: an international survey, Intensive Care Med 39 (2013) 1048-1056. https://doi.org/10.1007/s00134-0132872-5.

[9] Temnorarv guidelines "Prevention. diagnosis and treatment of new coronavirus infection (COVID19)." Version 6 (annroved bv the Ministrv of Health on 04/28/2020), httn://www.consultant.ru/document/cons doc LA W_351659/.

[10] K. Tran, K. Cimon, M. Severn, C.L. Pessoa-Silva, J. Conly, Aerosol Generating Procedures and Risk of Transmission of Acute Respiratory Infections to Healthcare Workers, A Systematic Review. PLoS One, 7(4): e35797, 2012, Published online 2012 Apr 26, DOI: 10.1371/journal.pone.0035797.

[11] J. Raboud, A. Shigayeva, A. McGeer, E. Bontovics M., Chapman, D. Gravel, et al. Risk factors for SARS transmission from patients requiring intubation: a multicentre investigation in Toronto, Canada, PLoS One, May 19; 5(5):e10717, DOI:10.1371/journal.pone.0010717.

[12] G.A. Kharchenko, M.Yu. Klischenko, I.V. Grigorieva, V.V. Kovalenko, Market researches of consumer properties of devices for carrying out inhalation based on the statistical processing of questionnaire results, Eruditio Juvenium 1 (2017) 89-101.

http://naukamolod.rzgmu.ru/art/276.http://naukamo lod.rzgmu.ru/art/276. DOI: 10.23888 /HMJ2017189-101/.

[13] G.A. Kharchenko, M.Yu. Klischenko, I.V. Grigorieva, V.V. Kovalenko, S.V. Semenova, Studying the Factors Influencing a Choice of Devices for Carrying Out Inhalations on the Basis of Statistical Processing of Results of Questionnaire, in: European Researcher. Series A, vol. 106(5), Is. 5, 2016, pp. 242-251. http://www.erjournal.ru/journals_n/1467662289. 